\title{
Isolation, Identification, and Antimicrobial Susceptibility Test of Bacteria from Vulva Swab of African Pygmy Hedgehog (Atelerix albiventris) and Sunda Porcupine (Hystrix javanica)
}

\author{
Anindya Dwi Ash-Santri ${ }^{1}$, Vinsa Cantya Prakasita ${ }^{2}$, Yosua Kristian Adi $^{3}$, Teguh \\ Budipitojo $^{4}$, and Agnesia Endang Tri Hastuti Wahyuni ${ }^{5 *}$ \\ ${ }^{1}$ Student in Faculty of Veterinary Medicine, Universitas Gadjah Mada, Indonesia \\ ${ }^{2}$ Department of Biology, Faculty of Biotechnology, Universitas Kristen Duta Wacana, Indonesia \\ ${ }^{3}$ Department of Reproduction and Obstetrics, Faculty of Veterinary Medicine, Universitas Gadjah \\ Mada, Indonesia \\ ${ }^{4}$ Department of Anatomy, Faculty of Veterinary Medicine, Universitas Gadjah Mada, Indonesia \\ ${ }^{5}$ Department of Microbiology, Faculty of Veterinary Medicine, Universitas Gadjah Mada, Indonesia
}

\begin{abstract}
Atelerix albiventris and Hystrix javanica are currently traded as pets or consumed in Indonesia, but there has been no research about bacteria from the vulva swab before. This research aims to isolate and identify bacteria from the vulva swabs of Atelerix albiventris and Hystrix javanica, and identify their antibiotic susceptibility. Samples were isolated by blood agar plates and selective media and identified by biochemical tests. Kirby Bauer's disk diffusion method was used for the antimicrobial susceptibility test. The result showed that from Atelerix albiventris was isolated and identified Escherichia coli and Proteus mirabilis, while from Hystrix javanica was isolated and identified Escherichia coli. The identified Escherichia coli was sensitive to Amikacin, Amoxycillin, Ampicillin, Enrofloxacin, Fosfomycin, Chloramphenicol, Tetracycline, Trimethoprim, and Kanamycin; intermediate to Streptomycin; and resistant to Erythromycin and Penicillin G. The identified Proteus mirabilis was sensitive to Amikacin, Amoxycillin, Kanamycin, Enrofloxacin, and Fosfomycin; and resistant to Erythromycin, Penicillin G, Streptomycin, Ampicillin, Chloramphenicol, Tetracycline, and Trimethoprim. This research concludes that Escherichia coli and Proteus mirabilis were isolated from vulva swab of Atelerix albiventris and Hystrix javanica, Escherichia coli was sensitive to eight antibiotics, while Proteus mirabilis was sensitive to five antibiotics.
\end{abstract}

* Corresponding author : wahyun_aeth@ugm.ac.id 


\section{Introduction}

Atelerix albiventris and Hystrix javanica have similar visuals with their quills covered the body surface. However, these two species are from a different order. Atelerix albiventris is classified as Eulipotyphla and comes from Africa [1], while Hystrix javanica is classified as Rodentia and is an endemic animal of Indonesia [2]. These two exotic species are often used as pets or consumed in Indonesia. Based on International Union for the Conservation Nature (IUCN) 2016, Atelerix albiventris and Hystrix javanica are categorized as Lower Risk-Least Concern and Least Concern, respectively which means the population in nature is still abundant. However, The Indonesian government issued a government regulation that includes Hystrix javanica as protected animals since 2018 because of the massive decrease of their population in nature due to hunt. Hunting was done because this porcupine is considered as a pest that destroys gardens and there is a belief that the porcupine meat and thorns have properties to cure diseases [3].

The female hedgehog and porcupine have a reproductive tract located caudally to the abdominal cavity [4]. The uterus is of a bicornu type with a short cornu and a long corpus to the cervix. The vagina is long without a vestibule. The external orifice separates the urinary tract and the vaginal opening, which is located near the clitoris. The opening of the vulva is under the anus $[4,5]$. The vulva is the outermost genital organ so that feces can contaminate the reproductive tract through the vulva. Apart from feces, contamination can come from urine where the reproductive tract and urinary tract attach to the vulva. Contamination can also come from the environment around the hedgehog and porcupine. One of the contaminations is bacteria. Escherichia coli, Proteus sp., Pseudomonas sp., Shigella sp., Yersinia sp., Klebsiella $s p$., and Salmonella sp. has been reported to be found in the gastrointestinal of southern white hedgehogs [6], whereas data regarding the type of bacteria and the sensitivity of bacteria to antibiotics from the reproductive tract of female hedgehogs and porcupine, especially the vulva, are not yet available.

This research aims to isolate, identify bacteria from the vulva swabs of Atelerix albiventris and Hystrix javanica, and identify antibiotic susceptibility. The results of this study will provide information about the bacteria found in the vulva of healthy female Atelerix albiventris and Hystrix javanica and their sensitivity to antibiotics.

\section{Methodology}

\subsection{Ethical approval}

Permission for this research was granted by the Chairman of the Research Ethics Commission of the Faculty of Veterinary Medicine, Universitas Gadjah Mada, Yogyakarta. Verbal consent from each related party was given after explaining the research objectives prior to sampling.

\subsection{Sample collection}

Two females Atelerix albiventris and one female Hystrix javanica were restrained with proper tools so they could not move and not harm. Sterile cotton swab and cotton bud that have been wetted with physiological $\mathrm{NaCl}$ sterile were used to swab the inner vulva. Sample 1, 2, and 3 were samples from the first female Atelerix albiventris, second female Atelerix albiventris, and female Hystrix javanica, respectively. The samples were put in the Broth Heart Infusion (BHI) for transport media. Isolation, identification, and antimicrobial 
susceptibility tests were carried out at Microbiology Laboratory, Faculty of Veterinary Medicine, Universitas Gadjah Mada.

\subsection{Isolation and Identification}

Three samples were inoculated in a blood agar plate (BAP), selective media Eosin Methylene Blue (EMB), and Mac Conkey agar (MCA) as an aerobic and anaerobic with the temperature of $37^{\circ} \mathrm{C}$ for 24 hours. Bacterial identification was carried out by observing the morphology of bacterial colonies on BAP, EMB, and MCA media, bacterial cell morphology using Gram staining, and bacterial characteristics using biochemical tests. The isolated pure bacterial culture was then inoculated on BHI media and incubated at $37^{\circ} \mathrm{C}$ for 24 hours [7] as a stock culture. Biochemical tests carried out in this study included the catalase test, oxidase test, urease test, carbohydrate fermentation test, IMViC test, and TSIA media.

\subsection{Antimicrobial Susceptibility Test}

The pure culture that has been identified is then tested for antibiotic sensitivity by the Kirby-

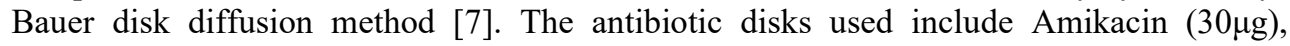
Amoxycillin $(25 \mu \mathrm{g})$, Ampicillin $(10 \mu \mathrm{g})$, Enrofloxacin $(5 \mu \mathrm{g})$, Erythromycin $(15 \mu \mathrm{g})$,

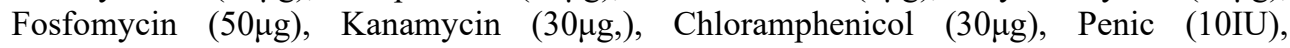
Streptomycin $(30 \mu \mathrm{g})$, Tetracycline $(30 \mu \mathrm{g})$, and Trimethoprim $(5 \mu \mathrm{g})$. Bacterial suspensions were prepared by inoculating pure cultures on $\mathrm{BHI}$ media and incubated at $37^{\circ} \mathrm{C}$ for 24 hours. Turbidity was adjusted by McFarland 0.5 or $1.5 \times 108 \mathrm{CFU} / \mathrm{ml}$ [8]. Antibiotic discs were arranged at a certain distance on the surface of Muller Hinton Agar media which had been inoculated with bacterial suspension and incubated at $37^{\circ} \mathrm{C}$ for 24 hours [9]. The diameter of the inhibition zone formed was measured by sensitive, intermediate, and resistance interpretations according to the standard [10].

\section{Results}

The results of isolation and identification showed that there were two types of bacteria in the vulvar swab samples. Escherichia coli can be isolated and identified from the first hedgehog vulva swab (sample 1 aerobic) and porcupine vulva swab (sample 3 aerobic and anaerobic), while Proteus mirabilis can be isolated and identified from the first hedgehog vulva swab (sample 1 anaerobic) and the second hedgehog vulva swab (sample 2 aerobic and anaerobic). Proteus mirabilis was not isolated and identified from porcupine vulvar swabs.

Table 1. Results of isolation and identification of bacteria from vulvar swab samples.

\begin{tabular}{ccccccc}
\hline \multirow{2}{*}{$\begin{array}{c}\text { Biochemical } \\
\text { Test }\end{array}$} & \multicolumn{3}{c}{ Escherichia coli } & \multicolumn{3}{c}{ Proteus mirabilis } \\
\cline { 2 - 7 } & $\begin{array}{c}\text { Sample } \\
\text { 1a }\end{array}$ & $\begin{array}{c}\text { Sample } \\
\text { 3a }\end{array}$ & $\begin{array}{c}\text { Sample } \\
\text { 3an }\end{array}$ & $\begin{array}{c}\text { Sample } \\
\text { 1an }\end{array}$ & $\begin{array}{c}\text { Sample } \\
\text { 2a }\end{array}$ & $\begin{array}{c}\text { Sample } \\
\text { 2an }\end{array}$ \\
\hline BAP & $\gamma$ & $\gamma$ & $\gamma$ & $\gamma$ & $\gamma$ & $\gamma$ \\
\hline EMB & $G M S$ & $G M S$ & $G M S$ & Colorless & Colorless & Purple \\
\hline MCA & Pink & Pink & Pink & Colorless & Colorless & Colorless \\
\hline Gram stain & Rod $^{-}$ & Rod $^{-}$ & Rod $^{-}$ & Rod- & Rod- & Rod $^{-}$ \\
\hline Catalase & + & + & + & + & + & + \\
\hline Oxidase & - & - & - & - & - & - \\
\hline Urease & - & - & w + & + & + & + \\
\hline
\end{tabular}

Fermented Carbohydrates

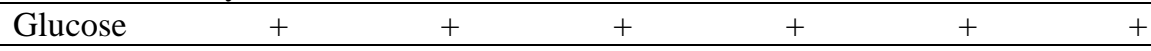




\begin{tabular}{|c|c|c|c|c|c|c|}
\hline Sucrose & - & + & - & - & - & - \\
\hline Lactose & + & + & + & - & - & - \\
\hline Galactose & + & + & + & + & + & + \\
\hline Sorbitol & + & + & + & - & - & - \\
\hline Mannitol & + & + & + & - & - & - \\
\hline Maltose & + & + & + & - & - & - \\
\hline \multicolumn{7}{|l|}{ IMViC } \\
\hline Indole & + & + & + & - & - & - \\
\hline Methyl Red & + & + & + & + & + & + \\
\hline$V P$ & - & - & - & - & - & - \\
\hline Citrate & - & - & - & - & - & + \\
\hline \multicolumn{7}{|c|}{ Triple Sugar Iron Agar (TSIA) } \\
\hline Slant & $\mathrm{Y}$ & $\mathrm{Y}$ & $\mathrm{Y}$ & $\mathrm{R}$ & $\mathrm{R}$ & $\mathrm{R}$ \\
\hline Butt & $\mathrm{Y}$ & $\mathrm{Y}$ & $\mathrm{Y}$ & $\mathrm{Y}$ & $\mathrm{H} 2 \mathrm{~S}$ & $\mathrm{H}_{2} \mathrm{~S}$ \\
\hline Precipitates & - & - & - & - & + & + \\
\hline
\end{tabular}

Sample 1: first hedgehog; Sample 2: second hedgehog; Sample 3: Sunda porcupine; a: aerobic; an: anaerobic; BAP: Blood Agar Plat; EMB: Eosin Methylene Blue; MCA: MacConkey Agar; GMS: Green Metallic Sheen; y: non-hemolytic; Rod': Rod, Gram negative; +: Positive; -: Negative; w+: Partial pink; Y: Yellow; R: Red

Three E. coli isolates from vulval swab samples showed $100 \%$ sensitivity to the antibiotics Amikacin, Amoxicillin, Ampicillin, Enrofloxacin, Phosphomycin, Chloramphenicol, Tetracycline and Trimethoprim; $66.7 \%$ sensitive to Kanamycin; $66.7 \%$ intermediates to Streptomycin; 100\% resistant to Erythromycin and Penicillin G; and 33.3\% resistant to Kanamycin and Streptomycin (Fig. 1).

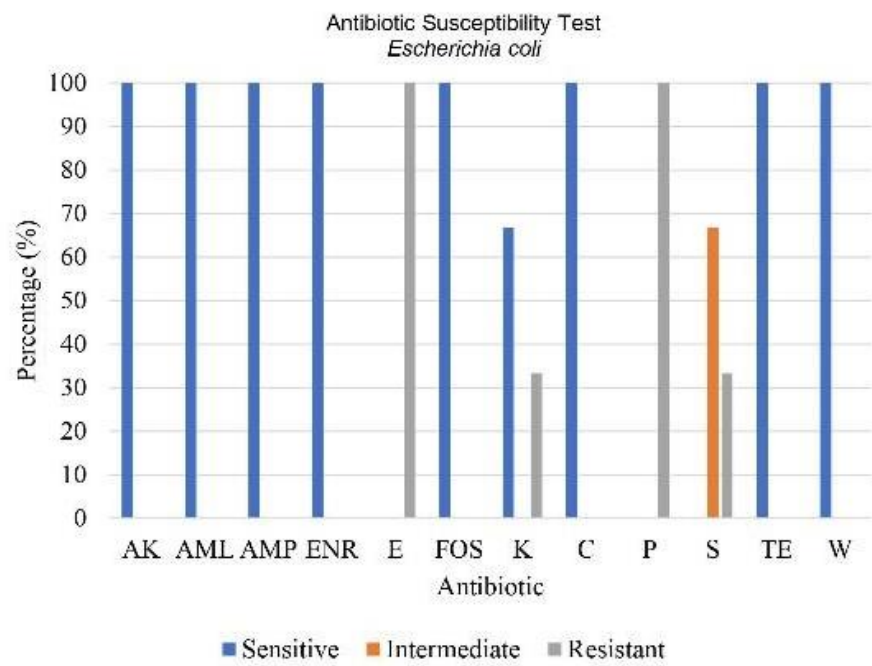

Figure 1. Susceptibility test of Escherichia coli. AK: Amikacin; AML: Amoxicillin; AMP: Ampicillin; ENR: Enrofloxacin; E: Erythromycin; FOS: Phosphomycin; K: Kanamycin; C: Chloramphenicol; P: Penicillin G; S: Streptomycin; TE: Tetracyclines; W: Trimethoprim.

None of the three $P$. mirabilis isolates from vulval swab samples showed $100 \%$ sensitivity; $66.7 \%$ sensitive to Amikacin, Amoxicillin, Kanamycin, Enrofloxacin, and Fosfomycin; and $33.3 \%$ sensitive to Ampicillin and Trimethoprim. There were $33.3 \%$ intermediate results against Amikacin, Enrofloxacin, Fosfomycin, Chloramphenicol, and 
Tetracycline. P. mirabilis isolates were $100 \%$ resistant to Erythromycin, Penicillin G and Streptomycin; 66.7\% resistant to Ampicillin, Chloramphenicol, Tetracycline and Trimethoprim; and 33.3\% resistant to Ampicillin and Kanamycin (Fig. 2).

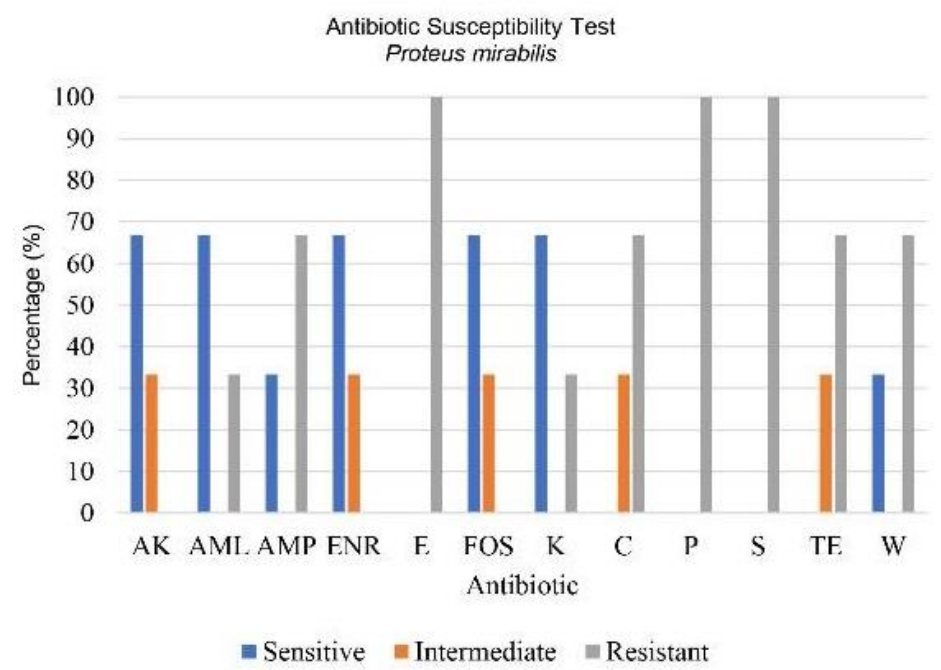

Figure 2. Susceptibility test of Proteus mirabilis. AK: Amikacin; AML: Amoxicillin; AMP: Ampicillin; ENR: Enrofloxacin; E: Erythromycin; FOS: Phosphomycin; K: Kanamycin; C: Chloramphenicol; P: Penicillin G; S: Streptomycin; TE: Tetracyclines; W: Trimethoprim.

\section{Discussion}

The bacterial characteristics of the isolates sample 1a, sample $3 \mathrm{a}$, and sample 3 an are in accordance with the characteristics of Escherichia coli such as $\gamma$-hemolytic on BAP media, green metallic sheen colonies on EMB, pink colonies on MCA, positive catalase, negative oxidase, negative urease, can ferment glucose, lactose, galactose, sorbitol, mannitol, and maltose, IMViC assay respectively $(+/+/-/-)$ [11], on TSIA media bacteria can ferment carbohydrates without gas production. There are differences in the yield of sucrose fermentation. Isolates sample 1a and sample 3an show negative results while sample 3a shows positive results, but this is in accordance with the report from Markey et al. (2013) where the ability of Escherichia coli to ferment sucrose is $26-75 \%$ so that the test has the opportunity to show positive or negative results [11].

The bacterial characteristics of the isolates sample $2 \mathrm{a}$, sample $1 \mathrm{an}$, and sample 2 an have similarities with the characteristics of Proteus mirabilis such as $\gamma$-hemolytic type in PAD, purple or colorless colonies on EMB media, colorless colonies on MCA media, positive catalase, negative oxidase, urease positive, can ferment glucose and galactose, unable to ferment sucrose, lactose, sorbitol, mannitol, and maltose, IMViC test was consecutively (- / $+/-/$ d) [11]. There is a difference in TSIA media, namely the isolate sample $2 \mathrm{a}$ and sample 2 an reduce peptone on the slant and there is an $\mathrm{H}_{2} \mathrm{~S}$ product, while the isolate sample 1an reduces peptone without any $\mathrm{H}_{2} \mathrm{~S}$ product. According to Markey et al. (2013), Proteus mirabilis can ferment carbohydrates without $\mathrm{H}_{2} \mathrm{~S}$ products.

Escherichia coli and Proteus mirabilis are members of the Enterobacteriaceae which are opportunistic pathogens and are normally found in the large intestine and lower small intestine of mammals [11]. In addition, Escherichia coli and Proteus mirabilis can be found in the reproductive tract of female animals $[11,12,13,14]$ and in the urine $[11,15]$. In the gastrointestinal tract, Erinaceus concolor or southern white hedgehog proved Escherichia coli (34.5\%) and Proteus mirabilis (27.5\%) [6]. Escherichia coli and Proteus mirabilis 
bacteria found in hedgehog and porcupine vulva swabs can come from outside the body either from the environment, feces from the anus, or bacteria from the urinary tract. The hedgehog and porcupine's vulva are located under the anus so that during defecation, bacteria in the feces can enter the vulva. Cages and cages that are rarely cleaned of feces or food residue can also be a source of bacteria that can enter the vulva. In certain circumstances, such as during mating or childbirth, the cervix will open so that the bacteria on the vulva can enter the upper genital tract.

Escherichia coli isolates showed higher sensitivity to Amikacin, Amoxicillin, Ampicillin, Enrofloxacin, Phosphomycin, Chloramphenicol, Tetracycline, and Trimethoprim and showed higher resistance to Erythromycin and Penicillin. Proteus mirabilis is quite sensitive to Amikacin, Amoxicillin, Kanamycin, Enrofloxacin, and Phosphomycin and shows higher resistance to Erythromycin, Penicillin G, and Streptomycin. The resistance of Escherichia coli and P. mirabilis to antibiotics that have been identified can be due to the fact that these animals have received treatment with certain antibiotics, received antibiotics as feed additives, or are contaminated with bacteria that are resistant from the environment so that the Escherichia coli and Proteus mirabilis isolates become resistant. However, this cannot be ascertained due to limited data from the sample used.

\section{Conclusion}

Escherichia coli and Proteus mirabilis were isolated from swabs of Atelerix albiventris and Hystrix javanica. Both bacteria are still quite sensitive to antibiotics, but Escherichia coli is more sensitive to several antibiotics than Proteus mirabilis which has more resistance than Escherichia coli. Hygiene and sanitation need to be considered during maintenance so that bacterial contamination can be minimized. In addition, treatment with antibiotics and the use of feed additives in the form of antibiotics also need attention.

\section{References}

1. F. Cassola. The IUCN Red List of Threatened Species: e.T40602A115174097 (2016)

2. K. Aplin, The IUCN Red List of Threatened Species: e.T10752A22231749 (2016)

3. W. R. Farida, Jurnal Biologi Indonesia 9, 311-325 (2013)

4. E. M. Santana, H. E. Jantz and T. L. Best, Mammalian Species 42, 99-110 (2010)

5. P. Mayor, M. Lopez-Bejar, F. Jori, M. Fenech, F. Lopez-Gatius, Elsevier: Animal Reproduction Science 77, 247-259 (2003)

6. P. Zare and H. Ghorbani-Choboghlo, J. of Exo.Pet Med. 24, 235-239 (2015)

7. H. J. Benson, Microbiological Applications: A Laboratory Manual in General Microbiology Eighth Edition (2001)

8. World Health Organization, WHO Regional Office for South-East Asia (2011)

9. M. J. Leboffe and B. E. Pierce, A Photographic Atlas for The Microbiology Laboratory Fourth Edition (2011)

10. CLSI, Performance Standards for Antimicrobial Susceptibility Testing $27^{\text {th }}$ Edition. (PA: Clinical and Laboratory Standards Institute, Wayne, 2017)

11. B. Markey, F. Leonard, M. Archambalt, A. Cullinane, D. Maguire, Clinicumaral Veterinary Microbiology Second Edition (2013)

12. B. Larsen, A. J. Markovetz, R. P .Galask, Applied and Environmental Microbiology 34, 534-540 (1977) 
13. M. Kostandi, C. Voidarou, A. Papadaki, A. Tsiotsias, O. Kotsovolou, W. Evangelou, E. Bezirtzoglou, Microbial Ecology in Health and Disease 18, 161-169 (2006)

14. N. M. Ayyal, Z. A. Abbas, A. J. Karim, Z. M. Abbas, K. A. Al-Salihi, D. D. Mahmood, E. A. Mohammed, R. S. Jumaa, D. I Abdul-Majeed, Veterinary World 12, 119-125 (2019)

15. D. Drzewiecka, Microb Ecol. 72, 741-758 (2016) 